\title{
How we approach localized vascular anomalies
}

\author{
Kristy Pahl ${ }^{1}$, Waleska Pabon-Ramos ${ }^{1}$, and Michael Jeng ${ }^{2}$ \\ ${ }^{1}$ Duke University Medical Center \\ ${ }^{2}$ Stanford University Medical Center
}

April 3, 2021

\begin{abstract}
Vascular anomalies are a group of disorders divided into two distinct subtypes: vascular tumors and vascular malformations. Vascular tumors are proliferative in nature, while malformations are non-proliferative. Simple, localized vascular malformations refer to a group of malformations that are localized to a single area of involvement. These simple malformations include capillary, lymphatic, venous, and arteriovenous malformations. The pediatric hematologist and oncologist is becoming increasingly involved in the diagnosis and management of these disorders. This review presents four cases as a means to discuss the diagnosis, clinical and imaging features, and management strategies of simple, localized vascular malformations.
\end{abstract}

How We Approach Simple localized vascular malformations

Pahl KS ${ }^{1}$, Pabon-Ramos $\mathrm{WM}^{2}$, Jeng $\mathrm{MR}^{3}$

Department of Pediatrics, Duke University Medical Center, (2) Department of Radiology, Duke University Medical Center, (3) Department of Pediatrics, Stanford University School of Medicine

\section{Corresponding Author:}

Kristy Pahl MD Pediatric Hematology/Oncology Duke University Medical Center 330 Trent Drive, Room 383 Hanes House Durham NC 27710 919-684-3401 (phone) 919-681-7950 (fax) kristy.pahl@duke.edu

\section{No conflict of interest}

Keywords: vascular malformation, venous malformation, lymphatic malformation, arteriovenous malformation, sclerotherapy

Word Count: Abstract- 97, Main text- 4149.Number of tables: 2. Number of Figures: 6

\section{Abbreviations:}

\begin{tabular}{ll}
\hline VM & Venous malformation \\
\hline LM & Lymphatic malformation \\
AVM & Arteriovenous malformation \\
CM & Capillary malformation \\
LIC & Localized intravascular coagulation \\
US & Ultrasound \\
MRI & Magnetic resonance imaging \\
CT & Computerized tomography \\
KMP & Kasabach-Merritt Phenomenon \\
VIR & Vascular Interventional Radiology
\end{tabular}




\begin{tabular}{ll}
\hline VM & Venous malformation \\
\hline KTS & Klippel-Trenaunay Syndrome \\
STS & Sodium tetradecyl sulfate \\
mTOR & Mammalian target of rapamycin \\
LMWH & Low molecular weight heparin \\
\hline
\end{tabular}

\section{I.ABSTRACT}

Vascular anomalies are a group of disorders divided into two distinct subtypes: vascular tumors and vascular malformations. Vascular tumors are proliferative in nature, while malformations are non-proliferative. Simple, localized vascular malformations refer to a group of malformations that are localized to a single area of involvement. These simple malformations include capillary, lymphatic, venous, and arteriovenous malformations. The pediatric hematologist and oncologist is becoming increasingly involved in the diagnosis and management of these disorders. This review presents four cases as a means to discuss the diagnosis, clinical and imaging features, and management strategies of simple, localized vascular malformations.

\section{INTRODUCTION}

The International Society for the Study of Vascular Anomalies (ISSVA) initially proposed, and continues to update, a widely held classification system for approaching vascular anomalies. There are two broad general groups: 1) tumors (which are proliferative in nature) and 2) malformations (which are non-proliferative in nature). Simple malformations refer to capillary (CM), lymphatic (LM), venous (VM), or arteriovenous malformations (AVM) (1). Malformations can be localized to a specific body area, or more extensive in nature. Vascular malformations are thought to arise from somatic mutations acquired during fetal development (2). Most will present at birth or in early childhood (3). They exhibit a wide variability of clinical impact ranging from asymptomatic lesions, to cosmetic concerns, and even life-threatening symptoms due to close proximity to vital structures such as the airway or lungs $(4,5)$. In general, clinical evaluation and imaging is usually diagnostic, but occasionally biopsy is needed if atypical features are present. Biopsy is not without risk, as lesions are prone to bleed. Immuno-histochemical markers and examination of vascular architecture can clarify diagnosis. CD34 confirms endothelial origin (6), while D2-40 (podoplanin) and LYVE-1 are associated with lymphatic vessels. CD31 and SMA stain positive in VMs (7). Genetic analysis of tissue will become more important as options for targeted therapy become increasingly available. In this review, we describe four cases and examine the clinical features, diagnostic options, and management strategies of simple, localized malformations. As a multi-disciplinary team is often needed to manage these complex patients, we will examine the role of multiple disciplines, including the pediatric hematologist and oncologist, in the care of patients with vascular malformations.

\section{CASES}

\section{Case 1: Localized venous malformation of the lower extremity}

A 13-year-old male presented with new onset swelling of the right lower extremity near his ankle (Figure 1). A mass was noted months earlier, but at time of presentation the lesion had increased in size causing daily pain, limiting use of the extremity. No other skin lesions were noted and the child was otherwise healthy. On physical exam, a $6 \mathrm{~cm} \times 6 \mathrm{~cm}$ soft, tender, palpable mass was present within the subcutaneous tissue of the ankle near the lateral malleolus. The overlying tissue demonstrated a slight bluish hue. No hardened nodules were palpated. Differential diagnosis included fatty tumors such lipoblastoma, inflammatory process (abscess, subcutaneous granuloma annulare), sarcoma, or vascular anomaly.

An ultrasound with Doppler demonstrated a compressible, heterogeneous lesion with low flow. Laboratory workup was significant for a platelet count of 175,000 (normal 150,000$450,000 \times 10^{9} / \mathrm{L}$ ), d-dimer of $455 \mathrm{ng} / \mathrm{ml}$ (normal $<500 \mathrm{ng} / \mathrm{ml}$ ), and fibrinogen of $250 \mathrm{mg} / \mathrm{ml}$ 
(normal 213-435 $\mathrm{mg} / \mathrm{ml}$ ). The patient was diagnosed with a pure venous malformation, and referred to vascular interventional radiology (VIR) for management.

Approachx $\backslash$

Background

VM are the most common type of vascular malformation, with an incidence of 1-2 per 10,000 births (2). VMs are typically located in the skin or mucosa, but can involve subcutaneous tissue, muscles, joints, nerves, and internal organs $(4,5,8)$. Most commonly, VMs present as soft subcutaneous masses with bluish colored overlying skin. They can enlarge with Valsalva maneuvers or on dependent positions (9). While VMs most commonly appear in childhood, delayed presentation in adolescence or adulthood can occur (3). Trauma, infection, hemorrhage, or hormonal changes during puberty or pregnancy can lead to growth $(4,10,11)$. Spontaneous regression does not occur (4). VMs can be focal or diffuse and may be associated with other malformation types in characterized syndromes, such as Klippel-Trenaunay Syndrome (KTS) (3). The majority of VMs are caused by gain-of-function mutations in the TIE-2 receptor $(12,13,14)$, which is integral to regulation of vascular proliferation, migration and adhesion $(14,15)$.

\section{Diagnosis}

The pediatric hematologist and oncologist is often called upon to distinguish between malignant versus benign masses, and vascular anomalies should be on the differential of a new onset mass. Clinical examination combined with imaging can generally lead to a diagnosis and rule out malignancy. Experienced clinicians and radiologists familiar with these entities are optimal. If unusual features are present on physical exam or imaging, or if concerning clinical history is present, biopsy must be considered. Caution must be taken with biopsy of vascular lesions given their propensity to bleed.

Under ultrasound examination, VMs appear as heterogeneous lesions typically containing anechoic vascular channels. The lesions are compressible if near the skin surface. VMs demonstrate slow flow, and Doppler analysis typically shows minimal to no color flow that can be augmented upon releasing compression or with Valsalva maneuvers. Spectral analysis reveals no waveforms or a monophasic venous waveform $(16,17)$. If Doppler does not demonstrate color flow and/or spectral waveforms, flow within the malformation may be too slow for sonographic detection, or vessels may have thrombosed (18). Slow blood flow contributes to the development of phleboliths, which are painful thrombosis and a common occurrence of VMs. On exam, they are palpated as hardened nodules (19). On US, they appear as a hyperechoic foci with posterior shadowing and are considered pathognomonic for VM (20).

As in this patient, on magnetic resonance imaging (MRI), VMs appear hyperintense on T2 weighted images (Fig 2). On T1 weighted images, they appear iso- or hypointense but may contain hyperintense areas representing blood products, fat, or calcifications. VMs enhance on T1 weighted images obtained after intravenous contrast administration. MRI not only aids in the classification of vascular malformations, but it also can determine lesion extent and relationship to surrounding structures $(21,22)$.

\section{Management}

The decision to treat a VM is dependent on location of the lesion, extension into adjacent tissue, presence of pain, functional impairment, or aesthetic appearance. Small, focal VMs which are not causing pain or functional impairment are often treated conservatively with observation alone. Compression garments improve vascular flow and reduce stasis, and help with pain. Custom compression garments are recommended to ensure proper fit and comfort, with typical pressures of $20-40 \mathrm{mmHg}(23,24)$. Compression should always be encouraged in VMs, as it can help prevent or slow the development of venous ectasia. Analgesics may be used for mild to moderate pain.

This patient had a small, focal, symptomatic VM which is amenable to sclerotherapy. Multiple rounds of sclerotherapy may be needed depending on lesion size and clinical symptoms. In this procedure, sclerosing agents are percutaneously injected into the VM. Sclerotherapy can be used alone for symptomatic relief, or 
in a staged approach in which pre-operative sclerotherapy is performed to improve success of subsequent excisional or debulking surgeries (25). The efficacy of sclerotherapy is generally related to the sclerosing agent and dwell time within the VM. Choice of sclerosing agent is dependent on a number of different factors, including VM location (depth, and proximity to adjacent structures), as well as ability to control venous drainage $(26,27)$. If robust venous drainage is present, occlusion of outflow veins is needed prior to injection of the sclerosing agent to prevent it from flowing out of the VM without proper endothelial contact time. Occlusion of venous drainage can be accomplished by use of a tourniquet, or by embolizing the outflow vein(s) with liquid embolic agents, coils or plugs (28). Table 1 lists a selection of commonly used sclerosing agents, their mechanism of action, and potential side effects. Given the superficial nature of the lesion described above, bleomycin or sodium tetradecyl sulfate (STS) would be acceptable choices. Alcohol should be avoided for lesions near nerves, superficial lesions, or VMs involving the mucosa given risk for inflammation, edema and necrosis which may affect nearby structures and damage surrounding tissues $(29,30)$. This patient had a positive response to sclerotherapy, with decreased swelling and minimal pain six months after treatment (Fig 3).

Surgical intervention can be considered in patients with symptomatic VMs if excision with appropriate margins does not injure vital structures. This approach may be appropriate for lesions which are not amenable to sclerotherapy. Depending on the extent of the lesion, surgery may or may not be curative, as VMs are prone to regrow if vascular tissue remains after surgery $(35,36)$. A surgical approach should focus on a defined anatomical area, preservation of critical neurovascular structures, and minimizing blood loss by staged approaches if needed (37).

While not applicable to this case as the patient had a localized VM amenable to sclerotherapy, patients with larger VMs not responsive to sclerotherapy or non-surgical candidates can consider the use of sirolimus. Sirolimus is an oral mammalian target of rapamycin (mTOR) inhibitor, which has been shown to be highly effective in patients with a wide variety of vascular anomalies. In patients with VM, multiple studies have described a benefit in reduction of lesion size and pain symptoms with the use of sirolimus (38). Sirolimus is generally dosed at $0.8 \mathrm{mg} / \mathrm{m} 2$ per dose every 12 hours, with monitoring of trough levels for dose adjustment. Target trough levels depend on lesion type, and the balance between treatment benefit and the potential for side effects. Potential side effects of sirolimus therapy include mucositis, count suppression, hypercholesterolemia, and increased liver enzymes. These side effects are reversible with either dose reduction or cessation of therapy (39). Patients receiving sirolimus are advised to seek medical attention with fevers and are prescribed prophylaxis against pneumocystis jiroveci pneumonia (PJP).

\section{Case 2: Localized venous malformation with Phleboliths}

A 5-year old female presents with left hand pain. At birth, she had a bluish hue to the fingernail of her left thumb along with a compressible, blue colored mass (Fig 4). At 18 months of age she underwent an MRI which was consistent with a VM. After her diagnosis of $\mathrm{VM}$, she was started on $3 \mathrm{mg} / \mathrm{kg}$ daily of aspirin given parenteral concerns of tenderness with palpation of the lesion. She is compliant with wearing a custom compression garment, but lately developed pain from her malformation despite aspirin therapy. Parents can occasionally palpate hardened nodules within the malformation, and also note a slight increase in the size of the VM. She has occasional short nosebleeds with dry weather, but no other bleeding symptoms. There is no significant family history of thrombosis or bleeding complications. She was initially examined by VIR, but referred to pediatric hematology given elevated d-dimer. Her most recent laboratory analysis revealed a platelet count of 275,000 (normal 150,000$450,000 \times 10^{9} / \mathrm{L}$ ), d-dimer of $1200 \mathrm{ng} / \mathrm{ml}$ (normal $<500 \mathrm{ng} / \mathrm{ml}$ ), fibrinogen of $272 \mathrm{mg} / \mathrm{ml}$ (normal $213-435 \mathrm{mg} / \mathrm{mL}$ ), partial prothrombin time of 28 seconds (normal 24 seconds - 32 seconds), and prothrombin time of 12 seconds (normal 11.5 seconds to 13.1 seconds).

Approach:

Background 
Localized intravascular coagulation (LIC) is common in patients with VMs. Large malformation size, involvement of deep structures, diffuse nature, and presence of palpable phleboliths are associated with the presence of LIC $(40,41)$. LIC is a consumptive coagulopathy, characterized by elevated d-dimer, and in more severe cases, low fibrinogen and thrombocytopenia. The exact mechanism driving LIC is unknown, but slow blood flow within malformed venous channels is thought to lead to activation of the coagulation system and consumption of clotting factors (42). Progression to overt DIC can occur in the setting of stressors such as infection (43), sclerotherapy (44), or surgery (45). It is important to distinguish LIC from the KasabachMerritt phenomenon (KMP), which occurs in vascular tumors such as kaposiform hemangioendothelioma and tufted angioma. LIC is characterized predominantly by clotting factor consumption, while KMP is characterized by platelet consumption and profound thrombocytopenia. This distinction is important, as the management of these two conditions is different (46). While thought to be rare, case reports of thromboembolic complications from VMs have been reported $(47,48,49)$. Increasing age, larger extent of malformation, and palpable phleboliths have been shown to be risk factors for thromboembolic complications $(49,50)$. As with the patient above, phleboliths can be present in VMs, and are palpated on physical exam as hardened nodules. They occur because of intravascular thrombi which calcify over time, and can be exquisitely painful (19).

\section{Management}

In this patient, symptomatic LIC was initially treated with aspirin. Aspirin may be helpful in selected patients, although no prospective studies have analyzed safety and efficacy. A retrospective survey of patients with VMs on aspirin reported $45 \%$ of participants obtaining a positive response, manifested as either less aching pain, less shooting pain, decreased fullness/swelling, and shrinkage of VM. Bleeding and bruising were reported complications (51). If aspirin does not improve symptoms, anti-coagulation can be considered. A thorough personal and family history of bleeding should be completed prior to initiation of anti-coagulation. Prior studies have documented a lack of response to vitamin K antagonists (46), and generally low molecular weight heparin (LMWH) is the agent of first choice. Patients are typically started on prophylactic dosing $(0.5 \mathrm{mg} / \mathrm{kg}$ twice a day) of LMWH, with appropriate monitoring of complete blood count, renal function, and LMWH levels. Treatment dosing of LMWH $(1.0 \mathrm{mg} / \mathrm{kg}$ twice a day) may be needed depending on patient response. Duration of treatment is variable, with patients requiring either episodic or continuous dosing (52). As the direct oral anti-coagulants become approved for use in children, these agents may play a more significant role in anti-coagulation for VM associated LIC. Case reports of their use in adult patients with VMs have shown improvement in LIC symptoms $(53,54)$.

Given the location on the hand, medical management was chosen. Surgical resection would be difficult and could lead to nerve or muscle damage, and similar concerns were present in regards to the potential complications of sclerotherapy. This patient was started on prophylactic dosing of lovenox with improvement in pain. If this patient had undergone sclerotherapy or surgical resection, discussion regarding the peri-procedural management of her LIC would be warranted. Unfortunately, there is a lack of evidence-based data to guide approach. The d-dimer threshold which places patients at risk for procedural complications, including both bleeding and thrombosis, is not known. Prior published guidelines from the Vascular Anomalies Special Interest Group of the American Society of Pediatric Hematology and Oncology recommended that patients with d-dimer greater than five times the upper limit of normal be administered LMWH for two weeks preand post-procedure (55).

\section{Case 3: Localized Lymphatic Malformation}

An 8-year-old male presented to his pediatrician for new onset right neck mass. He recently had a viral upper respiratory infection, and during this illness the mass became apparent. He was referred to pediatric hematology and oncology out of concern for malignancy. On further history, he denies fever, unintentional weight loss, or night sweats. His exam is notable for a mobile, tender, soft tissue mass measuring $2 \times 3 \mathrm{~cm}$ on the lower left neck. Range of motion was not inhibited. Overlying skin has a normal appearance. Ultrasound revealed a $3.0 \times 1.1 \times$ $2.6 \mathrm{~cm}$ complex subcutaneous lesion concerning for a vascular malformation. Complete blood 
count was unremarkable, LDH and uric acid were normal, d-dimer was $256 \mathrm{mg} / \mathrm{ml}$ (normal $<500 \mathrm{mg} / \mathrm{ml}$ ), fibrinogen 262 (normal $>150 \mathrm{mg} / \mathrm{dL}$ ), PTT 30 seconds (normal 24 seconds-32 seconds), and PT 14.5 seconds (normal).

Approach:

Background:

Prior to any imaging, when there is a question of type of malformation, screening labs are often obtained to help guide the clinician. In this case, a CBC, coagulation testing, d-dimer, and fibrinogen are our institution's standard screen. This cohort of tests helps rule out a vascular tumor which can be associated with KMP. Additionally, d-dimer can be used to help distinguish between malformation types, with LMs typically having normal d-dimer levels while VMs often have varying degrees of elevation (42).

LMs can present at birth, early childhood, or adolescence, and are most commonly located in the head and neck area. On exam, they are soft masses with often normal overlying skin, but can exhibit a bluish hue, or have associated lymphatic vesicles or blebs (11). LMs can be associated with other syndromes such as KTS or congenital lipomatosis overgrowth, vascular malformations, epidermal nevi and scoliosis/skeletal/spinal anomalies (CLOVES) (56). The majority of LMs are due to somatic mutations in the phosphatidylinositol4,5-biphosphonate 3-kinase catalytic subunit alpha (PIK3CA) gene (57). This gain of function mutation leads to a constitutively active PI3K/AKT/mTOR pathway, resulting in increased cell proliferation, survival and angiogenesis (56).There is a wide spectrum of clinical symptoms secondary to LMs, ranging from asymptomatic lesions to those that cause significant complications. Given their propensity for involvement of the head and neck area, functional impairment of the airway, feeding, or speech issues may arise in addition to cosmetic concerns (58). Increased pain and swelling can be associated with bacterial or viral infection, inflammation, trauma, or intra-lesional bleeding (59).

\section{Diagnosis}

As described in the vignette, on ultrasound exam, LMs present as multi-loculated cystic masses. Fluid levels may be present if the cystic spaces contain blood, pus or chyle $(60,61)$. LMs can be classified as either microcystic (less than $1 \mathrm{~cm}$ in size), macrocystic (greater than $1 \mathrm{~cm}$ in size) or mixed (62). The US image for this patient is seen in Fig 5A and 5B, and was consistent with a macrocystic LM. Similar to ultrasound, on MRI, LMs present as cystic masses. No solid enhancing component should be seen, unless a LM is microcystic in which case it can appear as a solid mass (61). Table 2 summarizes key imaging features of both LM and VM by imaging modality including US, CT and MRI.

\section{Treatment}

In asymptomatic patients without functional impairment or significant cosmetic concerns, careful observation is warranted. If treatment is indicated, options include surgery, sclerotherapy, or medical treatment with sirolimus; either alone or in combination. Surgical treatment for LM is most successful in patients with localized malformations that do not invade important adjacent structures (37), but debulking procedures for large, complex malformations may be indicated. Surgery could be offered to the patient above, but sclerotherapy is the most reasonable approach given high success rates with treatment of macrocytic lesions. Sclerotherapy is the first line treatment for macrocystic or mixed micro/macrocystic lesions (64), but is less efficacious for microcystic LMs (65). In microcystic lesions medical therapy with sirolimus has been shown to be beneficial in softening the lesions and also decreasing the size in general, leading to an improved quality of life (66).

Unless symptomatic, sclerotherapy is often not performed until the patient is at least 6 months of age. Given the location and symptomatic nature of the patient above, sclerotherapy would be the preferred treatment course for this patient. For treatment of LMs, a needle is inserted into the cystic space, lymphatic fluid is drained, and sclerosing agent is injected. Large cysts may require multiple injections over 24 to 48 hours, so a pigtail catheter is inserted to facilitate repeated injections $(37,64)$. Similar to VMs, success of sclerotherapy is dependent on the sclerosing agent used, dwell time, and type of LM. Higher rates of cure are seen in 
macrocystic LMs, as the entire endothelium can be treated. Doxycycline has the highest success rates for LM, with a meta-analysis of treated head and neck LM demonstrating an $80 \%$ efficacy rate (34). For lesions in the head and neck area, which involve the airway, orbit or are close to nerves, bleomycin, which causes minimal swelling, is the agent of choice (65). Dose dependent pulmonary toxicity is a potential complication of bleomycin therapy. Bleomycin doses in sclerotherapy are typically much smaller than the cumulative dose of $400 \mathrm{mg}$ or greater that is associated with toxicity (68). Macrocystic LMs respond well to treatment with OK-432, but microcystic or mixed lesions have a less favorable response (37). LMs can re-expand over time and require repeated procedures.

\section{CASE 4: Arteriovenous malformation}

An 9-year old previously healthy female presented for her regular annual well visit to her pediatrician, who noted a round, raised pulsating area over her right clavicular region (Fig 6). Her parents report that they noticed this about 3-4 months ago, and she denied pain, bleeding, or trauma to the area. She does endorse intermittent headaches of varying severity, occurring every 2 weeks, and not associated with visual changes. Acetaminophen and rest provide relief for the more severe headaches. Of note, there is no other medical history or family history of vascular issues or epistaxis.

approach:

\section{Background}

AVMs may present at any age and are the least common vascular malformation diagnosed in children (69). An AVM is a high flow lesion and occurs when an artery directly connects to the venous system and bypasses the capillary beds. The natural history of these abnormal vascular connections is progressively ectatic veins due to the high velocity blood flow, with eventual rupture. Rupture is the most feared complication for any AVM and therefore intervention is almost always warranted. The rate of rupture is higher in children when compared to adults, making timely intervention of higher consideration (70). High flow through AVMs can lead to hypoperfusion, hypoxic ischemia, and pain, in a phenomenon known as steal syndrome (71).

\section{Diagnosis}

AVMs can be found incidentally, or present with a wide variety of symptoms depending on location and size. On physical examination, auscultation typically demonstrates a bruit, which is due to abnormally high blood flow. Pulsation is a feature of AVMs as well (72). In this patient, an ultrasound revealed a vascular malformation in the musculature of the right neck/shoulder, with a clear communication with the right common carotid artery. The malformation exhibited venous flow, while the vascular connection demonstrated arterial waveforms. MRI with and without contrast showed an abnormal hypervascular lesion at the $\mathrm{C} 2$ level in the retropharyngeal space, extending inferiorly posterior to the carotid space. The arterial supply appeared to arise from the right subclavian artery and a small branch from the external carotid artery. She had no evidence of intra-cranial AVMs or steal syndrome.

When an AVM is diagnosed in a child, a complete family history and physical examination is warranted to assess the possibility for a systemic genetic syndrome such as hereditary hemorrhagic telangiectasia (HHT). HHT is inherited in an autosomal dominant fashion with variable penetrance. AVMs can occur in the brain, lungs, or liver in addition to mucosal telangiectasia. Early diagnosis is crucial so appropriate screening can be completed to avoid complications (73). In patients with AVMs, routine monitoring for high output heart failure is necessary depending on the degree of shunting across the AVM (74).

\section{Management}

The approach to management of AVMs is dependent on location, and they are classified as either intracranial or extracranial. A cranial lesion leads to the inclusion of neurosurgery to guide care. Otherwise, a multidisciplinary approach to clinical decisions will help to promote optimal outcomes through consideration of the risks and benefits of the treatment options for both types of AVMs. Traditionally procedures such as 
surgical endovascular resection, embolization using a chemical for glue, coil placement, and radiation therapy are considered the primary interventions for AVM management (75). Recently, several investigators have reported an association with somatic KRAS mutations and AVMs (76). These mutations lead to aberrant activation of the MAPK signaling pathway. Several case reports describe radiologic response to inhibition of this path with biologic agents, such as AKT inhibitors $(76,77)$. Therefore, medical therapies for AVMs may be new modalities for treatment in the future and several studies are underway (78).

Following her initial visit, the patients headaches resolved. Therefore, a non-urgent elective embolism with interventional radiology was recommended in the next year. The parents were asked to monitor for increased size or new symptoms. Approximately six months later, the patient re-presented with cramping pain in the right supraclavicular area and there was an increase in size of the AVM. A selective embolization utilizing n-butyl cyanoacrylate (Onyx) was performed (79). In addition, peri-procedural sirolimus was used in order to decrease post-embolism collateralization $(80,81)$. A cerebral angiogram was performed to allow better visualization of the anatomic vasculature, and revealed a malformation within the right upper thoracic and cervical regions, with significant blood supply from the thyrocervical trunk and common origin, ascending cervical, deep cervical and right occipital arteries. She underwent 3 embolization procedures, every 2 weeks, and had a good response. Her lesion became smaller both on clinical exam and by MRI imaging. She was asymptomatic and followed every 6 months for a year and then annually with both exam and MRI. She has been followed post procedure for 5 years without recurrence or increase in AVM. Of note, no genetic testing was performed due to lack of biopsy tissue sampling.

\section{Summary}

Simple, localized vascular malformations are composed of a heterogeneous population of lesions which include capillary, lymphatic, venous or arteriovenous malformations. Clinical symptoms vary widely, with many children having asymptomatic lesions which require expectant observation. Other children develop lesions which cause significant pain, functional, or cosmetic impairment and require a multi-disciplinary approach to their care. Diagnosis of simple vascular malformations is often accomplished through clinical exam and imaging, but biopsy is indicated if atypical features are present. Management of vascular malformations is dependent on type of malformation and lesion location, but can involve medical management, surgical resection, or sclerotherapy. The pediatric hematologist and oncologist is playing an ever-increasing role in the care of patients with vascular malformations. As our understanding of the genetic basis for vascular malformations grows, targeted therapy originally developed for oncologic indications, such as KRAS inhibitors, will play a more substantial role in the treatment of vascular malformations.

\section{References}

1. 2018 Classification. http://www.issva.org/classification. Published 2018. Accessed October 1, 2020.

2. Vikkula M, Boon LM, Mulliken JB. Molecular genetics of vascular malformations. Matrix Biol. 2001;20:327-335.

3. Boom LM, Ballieux F, Vikkula M. Pathogenesis of vascular anomalies.Clin Plast Surg. 2011;38:7-19.

4. Hassanein AH, Mulliken JB, Fishman SJ, Alomari AI, Zurakowski D, Greene AK. Venous malformations: risk of progression during childhood and adolescence. Ann Plast Surg . 2012;68:198-201.

5. Colletti G, Ieraradi IM. Understanding venous malformations of the head and neck: a comprehensive insight. Med Oncol . 2017;34(3): 896-899.

6. Sidney LE, Branch MJ, Dunphy SE. Concise review: evidence for CD34 as a common marker for diverse progenitors. Stem Cell . 2014;32(6):1380-1389.

7. Gupta A, Kozakewich H. Histopathology of vascular anomalies. Clin Plastic Surg. 2011;38:31-44.

8. Laurian C, Cerceau P, Paraskevas N, et al. Intramuscular venous malformations of the calf: surgical treatment outcomes of 57 patients. Phlebology . 2020;35(8):597-604.

9. Behravesh S, Yakes W, Gupta N, et al. Venous malformations: clinical diagnosis and treatment. Cardiovasc Diagn Ther . 2016;6(6):557-569.

10. Cahill AM, Nijs EL. Pediatric vascular malformations: pathophysiology, diagnosis and role of interventional radiology. Cardiovas Intervent Radiol . 2011;34(4):691-704. 
11. Bagrodia N, Defnet AM, Kandel JJ. Management of lymphatic malformations in children. Curr Opin Pediatr . 2015;27(3):356-363.

12. Nguyen HL, Boon LM, Vikkula M. Genetics of vascular malformations.Seminar Pediatr Surg . 2014;23:221-226.

13. Vikkula M, Boon LM, Carraway KL et al. Vascular dysmorphogenesis caused by an activating mutation in the receptor tyrosine kinase TIE2.Cell . 1996;87(8):1181-1190.

14. Limaye N, Wouters V, Ubelhoer M, et al. Somatic mutations in angiopoietin receptor gene TEK causes solitary and multiple sporadic venous malformations. Nat Genet . 2009;41(1):118-124.

15. Sato TN, Tozawa Y, Deutsch U, et al. Distinct roles of the receptor tyrosine kinase Tie-1 and Tie-2 in blood vessel formation. Nature. 1995;376:70-74.

16. Dubois J, Soulez G, Olivia VL, et al. Soft tissue venous malformations in adult patients: imaging and therapeutic issues.Radiographics . 2001;21(6):1519-1531.

17. Colletti G, Valassina D, Bertossi D, et al. Contemporary management of venous malformations. $J$ Oral Maxillofac Surg . 2014;72(3):510-528.

18. Johnson CM, Nararro OM. Clinical and sonographic features of pediatric soft tissue vascular anomalies part 2: vascular malformations.Pediatr Radiol . 2017;47(9):1196-1208

19. Eivazi B, Fasunla AJ, Guldner C, Masberg P, Werner JA, Teymoortash A. Phleboliths from venous malformations of the head and neck.Phlebology . 2013;28(2):86-92.

20. Trop I, Dubois J, Guibaud L, et al. Soft tissue venous malformations in pediatric and young adult patients: diagnosis with Doppler ultrasound. Radiology . 1999;212(3):841-845.

21. Flors L, Leiva-Salinas C, Maged IM, et al. MR imaging of soft-tissue vascular malformations: diagnosis, classification, and therapy follow-up. Radiographics . 2011;31:1321-1340.

22. Restrep R. Multi-modality imaging of vascular anomalies. Pediatr Radiol . 2013;43:141-154.

23. Langbrock GB, Horbach SE, Vanderleuten CJM, et al. Compression therapy for congenital low flow vascular malformations of the extremities- a systemic review. Phlebology . 2018;33(1):5-13.

24. Wang SK, Drucker NA, Gupta AK, et al. Diagnosis and management of Klippel-Trenaunay syndrome. J Vasc Surg Venous Lymphat Disord . 2017;5(4):587-595.

25. James CA, Braswell LE, Wright LB, et al. Pre-operative sclerotherapy of facial venous malformations: impact on surgical parameters and long term follow-up. J Vasc Interv Radiol . 2011;22:953-960.

26. Odeyinde SO, Kangesu L, Badran M, et al. Sclerotherapy for vascular malformations: complications and a review of techniques to avoid.J Plast Reconstr Aesthet Surg . 2013;66:215-223.

27. Hage AN, Chick JF, Srinivasa J, et al. Treatment of venous malformations: the data, where we are, how it is done. Tech Vasc Interv Radiol . 2018;21:45-54.

28. Pimpalwar S. Vascular malformations: approach by interventional radiology. Semin Plast Surg . 2014;28(2):91-193.

29. Greinwald JH, Burke DK, Sato Y, et al. Treatment of lymphangiomas in children: an update of picibanil (OK-432) sclerotherapy. Otolaryngol Head Neck Surg . 1999;121(4):381-387.

30. Tu JH, Do HM, Patel V, et al. Sclerotherapy for lymphatic malformations of the head and neck. Journal of Neurointerventional Surgery. 2017;9:1023-1026.

31. Albanese G, Kondo KL. Pharmacology of sclerotherapy. Semin Intervent Radiol. 2010;27(4): 391-399.

32. Zhang J, Li HB, Zhou SY, et al. Comparison between absolute ethanol and bleomycin for the treatment of venous malformations in children.Exp Ther Med. 2013;6(2):305-309.

33. Schaffer M, Walz E, Stormer K, et al. Health link: bleomycin alert. Children's oncology group. 2013.

34. de Maria L, Sanctis PD, Balakrishnan K, et al. Sclerotherapy for lymphatic malformations of the head and neck: systemic review and meta-analysis. J Vasc Surg Venous Lymphat Disord . 2020;8(1):154164.

35. Zhong LP, Ow A, Yang WJ, et al. Surgical management of solitary venous malformation in the midcheek region. Oral Surg Oral Med . 2012;114:160-166.

36. Loose DA. Surgical management of venous malformations.Phlebology. 2007;22(6):276-282.

37. Defnet AM, Bagrodia N, Hernandez SL et al. Pediatric lymphatic malformations: evolving understanding and therapeutic options.Pediatr Surg Int. 2016;32:425-433. 
38. Seront E, van Damme AN, Boon LA, et al. Rapamycin and treatment of venous malformations. Curr Opin Hematol . 2019;26:185-192.

39. Hammill AM, Wentzel MS, Gupta A, et al. Sirolimus for the treatment of complicated vascular anomalies in children. Pediatr Blood Cancer . 2011;57(6):1018-1024.

40. Hung JWS, Leung MWY, Liu CSW et al. Venous malformations and localized intravascular coagulopathy in children. Eur J Pediatr Surg . 2017;27(02):181-184.

41. Dompartin A, Acher A, Thibon P, et al. Association of localized intravascular coagulation with venous malformations. Arch Dermatol . 2008;144(7):873-877.

42. Zhou KY, Russell S, Wargon O, Adams S. Localized intravascular coagulation complicating venous malformations in children: associations and therapeutic options. J Pediatr Child Health . 2017;53(8):737741.

43. Han YY, Sun LM, Yuan SM. Localized intravascular coagulation in venous malformations: a system review. Phlebology . 2021;36(1):38-42.

44. Mason KP, Neufield EJ, Karian VE, et al. Coagulation abnormalities in pediatric and adult patients after sclerotherapy or embolization of vascular anomalies. Am J Roentgenol . 2001;177(6):1359-1363.

45. Griffith $\mathrm{CH}$, Herod J. Anesthesia for massive venous malformation and disseminated intravascular coagulation: strategies for minimizing blood loss: a case report. Ped Anesth Crit Care . 2015;3(1):2225.

46. Mazoyer O, Enjolras C, Laurian C, et al. Coagulation abnormalities associated with extensive venous malformations of the limb: differentiation from kasabach-merritt syndrome. Clin Lab Haematol . 2002;24(4):243-251.

47. Sing AC, Webb JL, Low DW, Chen AE. Pulmonary emboli associated with isolated lower-extremity venous malformation: a case report.Pediatr Emerg Care . 2013;29(3):371-373.

48. Hautier-Mazeereeuq J, Syed S, Leisner RI, Harper JI. Extensive venous/lymphatic malformations causing life threatening hematological complications. Br J Dermatol . 2007;157(3):558-563.

49. Nakano T, Zeinati C. Venous Thromboembolism in pediatric vascular anomalies. Front Pediatr . $2015 ; 5(158): 1-6$.

50. Sepulveda P, Zavala A, Zuniga P. Factors associated with thrombotic complications in pediatric patients with vascular malformations. J Pediatr Surg . 2016;52(3):400-410.

51. Nguygen JT, Koerper MA, Hess CP, et al. Aspirin therapy in venous malformations: a retrospective cohort study of benefits, side effects, and patient experiences. Ped Derm . 2014;31(5):556-560.

52. Adams DM. Special considerations in vascular anomalies: hematologic management. Clin Plast Surg . 2011; 38(1):153-160.

53. Vandenbriele C, Vanassche T, Peetermans M, Verhamme P, Peerlinck K. Rivaroxaban for the treatment of consumptive coagulopathy associated with a vascular malformation. J Thromb Thrombolysis . 2014;38(1):121-123.

54. Mack JM, Richter GT, Crary SE. Effectiveness and safety of treatment with direct oral anticoagulant rivaroxaban for slow-flow vascular malformations: a case series. Lymphat Res Biol . 2018;16(3):278281.

55. The American Society of Pediatric Hematology/Oncology. Vascular Anomalies Special Interest Group. Chicago, IL: The American Society of Pediatric Hematology/Oncology; 2015. Available from: http://aspho.org/membership/special-interest-groups/vascular-anomalies. Accessed August 1, 2020.

56. Luks VL, Kamitaki N, Vivero MP, et al. Lymphatic and other vascular malformative/overgrowth disorders are caused by somatic mutations in PIK3CA. J Pediatr . 2015;166(4):1048-1054.

57. Blesinger H, Kaulfub S, Aung T, et al. PIK3CA mutations are specifically localized to lymphatic endothelial cells of lymphatic malformations. PLOS One . 2018;13(7):1-18.

58. De Serres LM, Sie KC, Richardson MA, et al. Lymphatic malformations of the head and neck: a proposal for staging. Arch Otolaryngol Head Neck Surg. 1995;121(5):577-582.

59. Boardman SJ, Cochrange LA, Roebuck D, et al. Multimodality treatment of pediatric lymphatic malformations of the head and neck using surgery and sclerotherapy. Arch Otolaryngol Head Neck 
Surg . 2010;136(3):270-276.

60. Elluru RG, Balakrishnan K, Padua HM, et al. Lymphatic malformations: diagnosis and treatment. Seminars in Ped Surg . 2014;23(4):178-185.

61. White CL, Olivieri B, Restrep R, et al. Low flow vascular malformation pitfalls: from clinical examination to practical imaging evaluation. Am J of Rotentgenology . 2016;206(5):940-951.

62. Ma J, Biao R, Lou F, et al. Diagnosis and surgical treatment of cervical macrocystic lymphatic malformation in infants. Exp Ther Med. 2017;14(2):1293-1298.

63. Flis CM, Connor SE. Imaging of head and neck venous malformations. Eur Radiol . 2005;15:2185-2193.

64. Greene AK, Perlyn CA, Alomari AI. Management of lymphatic malformations. Clin Plast Surg . 2011;38:75-82.

65. Perkins JA, Manning SC, Tempero RM, et al. Lymphatic malformations: a review of current treatment. Otolaryngol Head Neck Surg . 2010;142(6):795-803.

66. Strychowsky JE, Rahbar R, O'Hare MJ, Padua H, Trenor CC. Sirolimus as treatment for 19 patients with refractory cervicofacial lymphatic malformation. Laryngoscope . 2018;128(1):269-276.

67. Mohan AT, Adams S, Adams K, et al. Intralesion injection of bleomycin in management of low flow vascular malformations in children. J Plast Surg and Hand Surg . 2015;49(2):116-120.

68. Chaudry G, Guevara CJ, Rialon KL, et al. Safety and efficacy of bleomycin sclerotherapy for microcystic lymphatic malformation. Cardiovasc Intervent Radiol. 2014;37:1476-1481.

69. Niazi TN, Klimo P Jr, Anderson RC, Raffel C. Diagnosis and management of arteriovenous malformations in children.Neurosurg Clin N Am . 2010;21(3):443-456.

70. El-Ghanem M , Kass-Hout T, Kass-Hout O et al. Arteriovenous Malformations in the Pediatric Population: Review of the Existing Literature. Interv Neurol. 2016;5(3-4):218-225.

71. Ajiboye N, Chalouhi N, Starke RM, et al. Cerebral AVM: evaluation and management. Scientific World Journal . 2014. 1-6.

72. Dinc N, Won SY, Quick-Weller J, Berkefeld J, Seifert V, Marquardt G. Prognostic variables and outcome in relation to different bleeding patterns in arteriovenous malformations. Neurosurg Rev . 2019;42(3):731-736.

73. Giordano P, Lenato GM, Suppressa P, et al. Hereditary hemorrhagic telangiectasia: arteriovenous malformations in children.J Pediatr . 2013;163(1):179-86.e1-3.

74. Liao Y, Chen K-H, Huang G-Y, Song W. Pulmonary arteriovenous malformations presenting as refractory heart failure. J Thorac Dis . 2014;6(9): E169-E172.

75. Bouwman FCM, Botden SMBI, Verhoeven BH, et al. Treatment Outcomes of Embolization for Peripheral Arteriovenous Malformations. J Vasc Interv Radiol . 2020;1(11):1801-1809.

76. Priemer DS, Vortmeyer AO, Zhang S, Chang HY Curless K. Activating KRAS mutations in arteriovenous malformations of the brain: frequency and clinicopathologic correlation. Hum Pathol . 2019;89:33-39.

77. Lekwuttikam R, Lim YH, Admani S Choate KJ, Teng J. Genotype-Guided Medical Treatment of an Arteriovenous Malformation in a Child.Jama Dermatol 2019;155(2):256-257.

78. Phelps EA, Cooke D, Frieden IJ, Zapala MA, Fullerton HJ, Shimano KA. Monitoring Arteriovenous Malformation Response to Genotype-Targeted Therapy. Pediatrics . 2020;146(3):e3206.

79. Hill H, Chick JF Hage. A, Srinivasa R. N-butyl cyanoacrylate embolotherapy: techniques, complications, and management.Diagn Interv Radiol. 2018; 24(2): 98-103.

80. Gabeff R, Boccara O, Soupre V, et al. Efficacy and Tolerance of Sirolimus (Rapamycin) for Extracranial Arteriovenous Malformations in Children and Adults. Acta Derm Venereol . 2019;99(12):1105-1109.

81. Cheliah MP, Do H, Zinn Z, et al. Management of Complex Arteriovenous Malformations Using a Novel Combination Therapeutic Algorithm.JAMA Dermatol. 2018;154(11):1316-1319.

\section{Hosted file}

Table 1.pdf available at https://authorea.com/users/405595/articles/516537-how-we-approachlocalized-vascular-anomalies

\section{Hosted file}


Table 2.pdf available at https://authorea.com/users/405595/articles/516537-how-we-approachlocalized-vascular-anomalies 


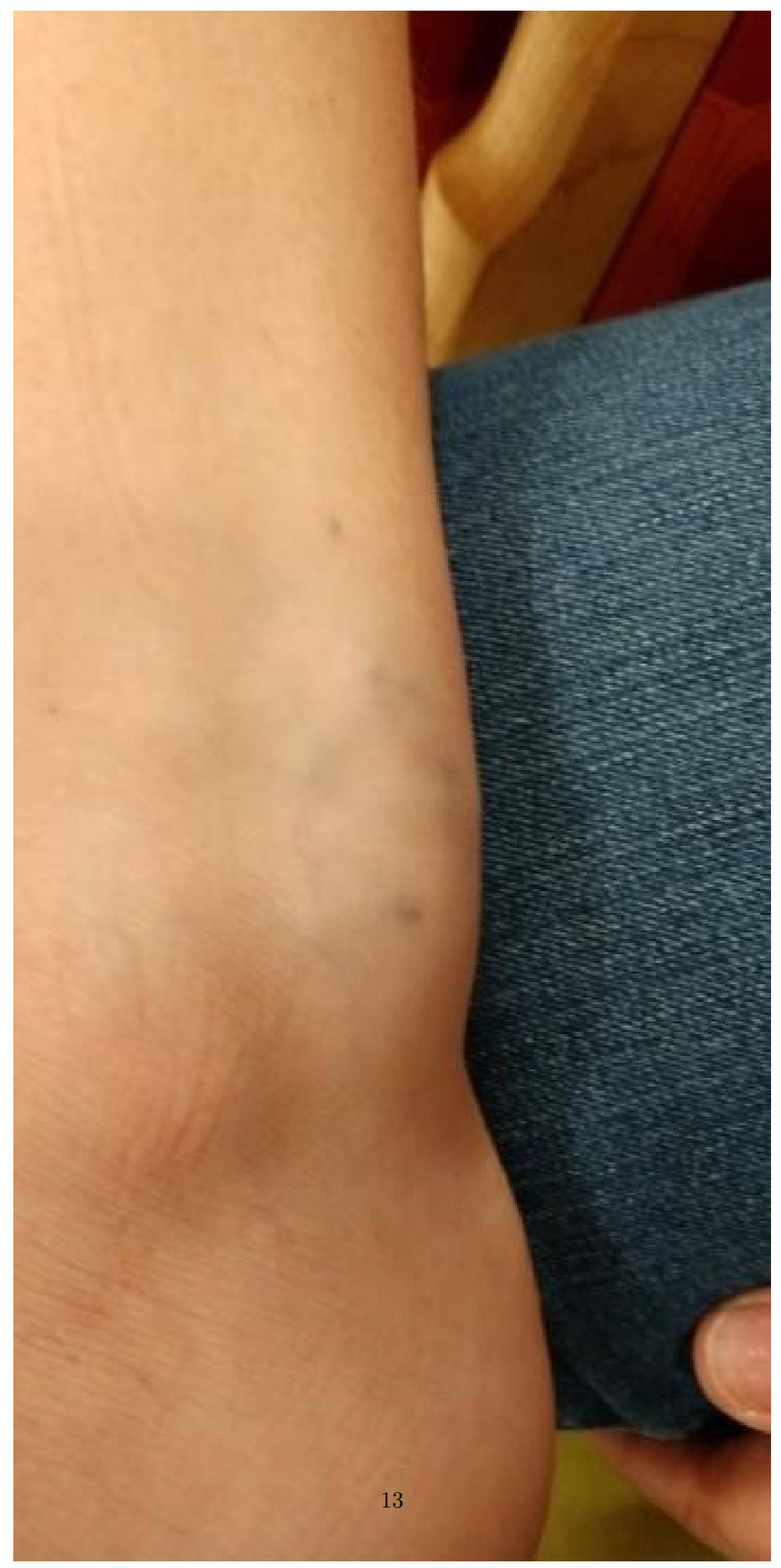




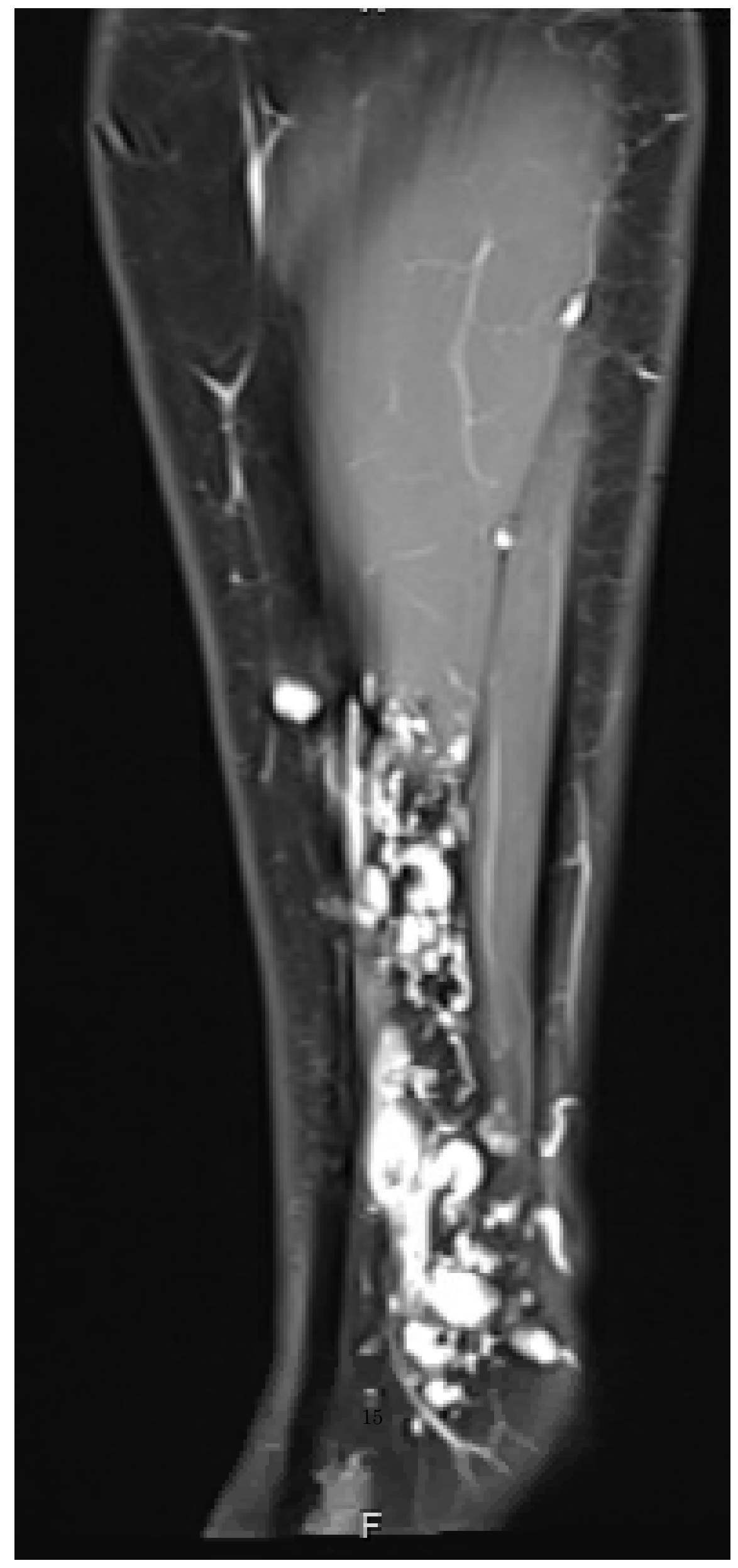




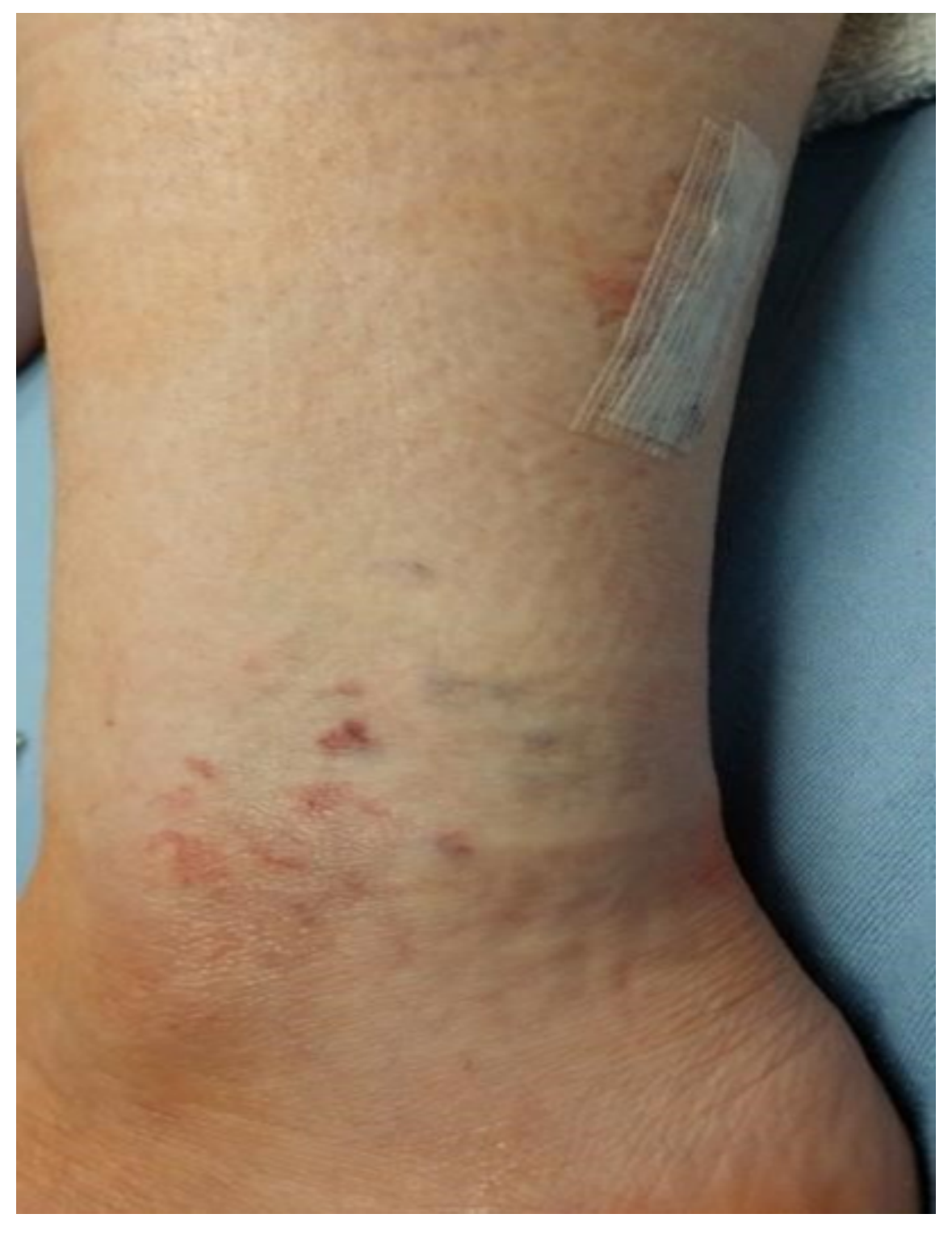



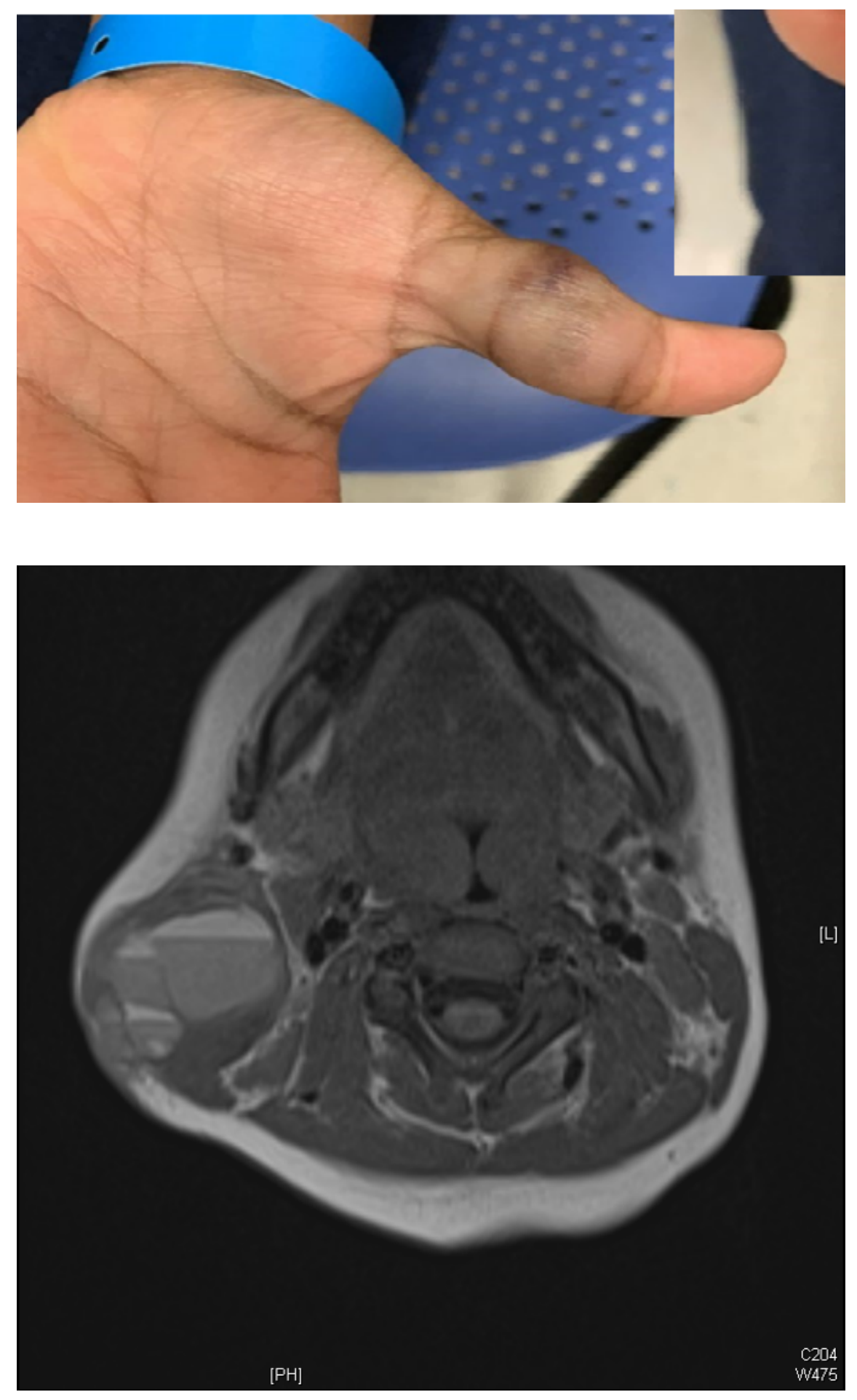


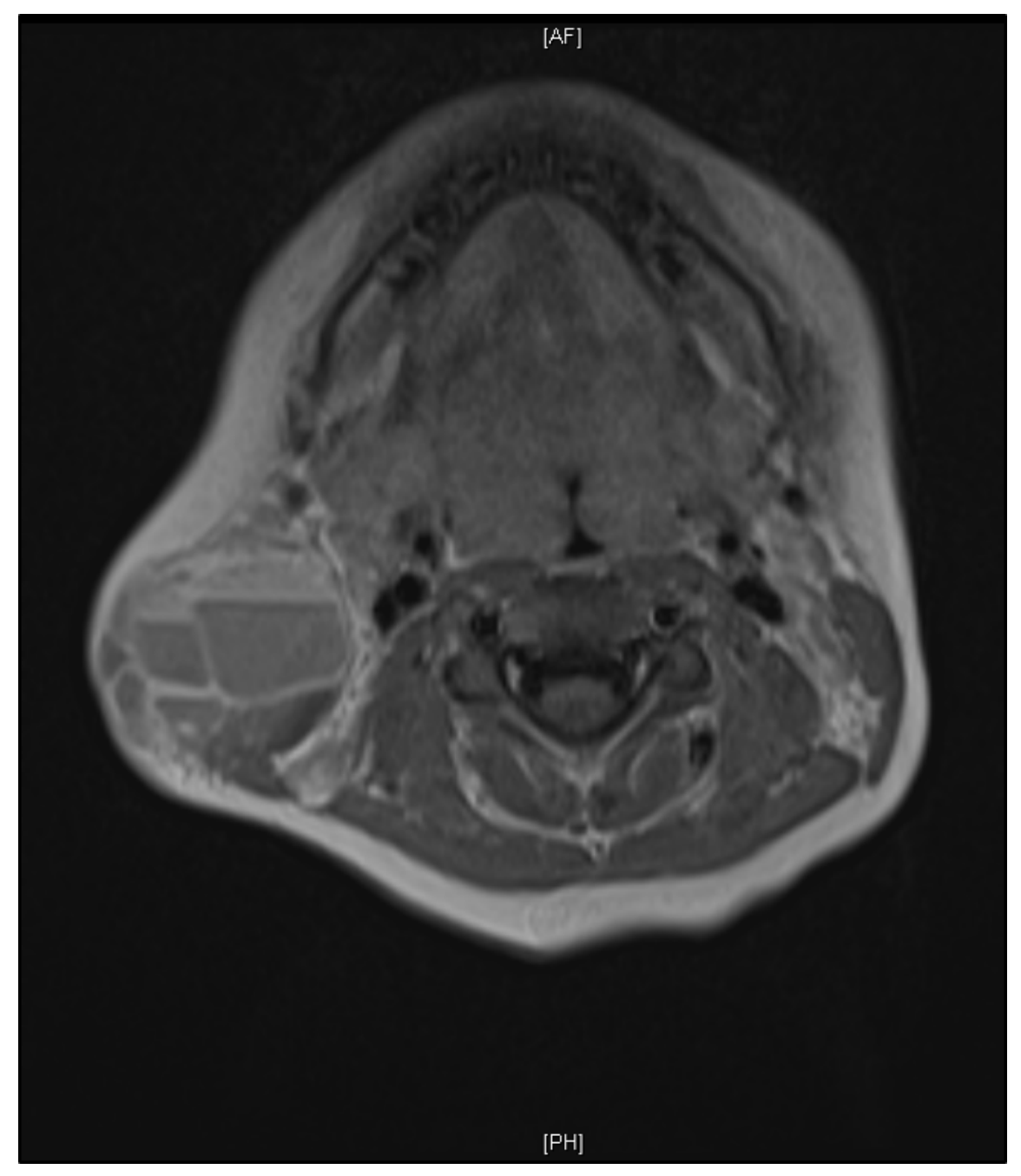




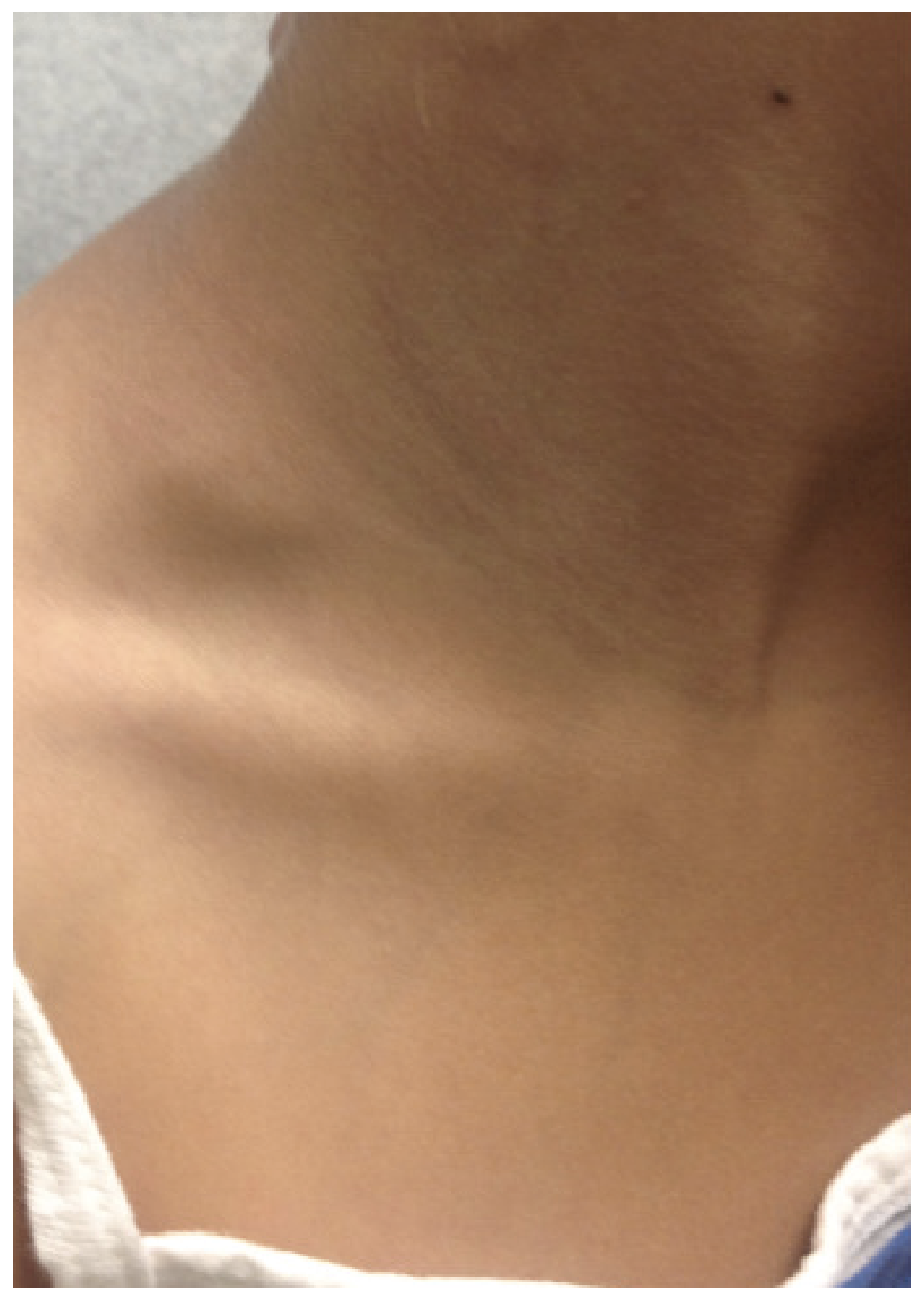

